\title{
Impact of endoscopic ultrasonography on the management of a prospective cohort of 700 consecutive patients referred for diagnostic endoscopic ultrasonography
}

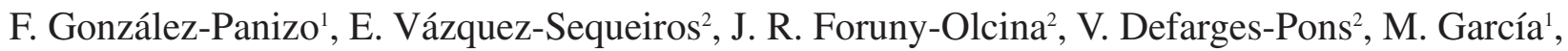 \\ D. Boixeda-de-Miquel' ${ }^{2}$, V. Moreira-Vicente ${ }^{2}$, D. Juzgado-Lucas ${ }^{1}$ and J. M. Milicua-Salamero ${ }^{2}$ \\ ${ }^{1}$ Endoscopy Unit. Digestive Diseases Department. Quirón University Hospital. Madrid, Spain \\ ${ }^{2}$ Endoscopy Unit. Gastroenterology Department. Ramón y Cajal University Hospital. Madrid, Spain
}

\begin{abstract}
Background: endoscopic ultrasonography (EUS) is a high accuracy technique for the study of many digestive diseases. The degree of knowledge about the impact of EUS on the management of these patients is inadequate.

Aim: to determine the therapeutic impact of endoscopic ultrasonography (EUS) on a prospective cohort of patients.

Methods: all patients referred for EUS over a period of 2 years were prospectively evaluated in order to asses: 1 . EUS provides new information not previously known; 2 . theoretic impact of EUS on patient management; 3. real impact of EUS on final therapy; 4 . changes in the aggressiveness of the therapeutic decision after EUS.

Results: 700 patients were included. Preoperative assessment of digestive tumors was the commonest indication. EUS provided "new information" in the $89 \%$ of the patients. With regard to endoscopist opinion, these findings should alter the management in $79 \%$ of patients ("theoretic impact"). However, EUS prompted a change in the management in $67 \%$ of patients ("real impact"). Final therapy post-EUS was less aggressive in 34\% of patients. Changes in therapeutic decision were associated with EUS findings, alcohol intake and age $\geq 57$ years old.

Conclusions: 1) EUS findings, advanced age, and alcohol intake are associated with a change in the management in 2 out of every 3 patients referred for EUS. 2) Therapeutic decision (postEUS) is less aggressive in a third of these patients, what should represent a significant economic saving.
\end{abstract}

Key words: Impact. Clinical impact. Cost-effectiveness. Usefulness. Endoscopic ultrasonography.
González-Panizo F, Vázquez-Sequeiros E, Foruny-Olcina JR, Defarges-Pons V, García M, Boixeda-de-Miquel D, Moreira-Vicente $V$, Juzgado-Lucas D, Milicua-Salamero JM. Impact of endoscopic ultrasonography on the management of a prospective cohort of 700 consecutive patients referred for diagnostic endoscopy ultrasonography. Rev Esp Enferm Dig 2011; 103: 62-68.

\section{INTRODUCTION}

Over the last 30 years, endoscopic ultrasonography (EUS) has achieved a great importance as a diagnostic tool (1-3). By now, its availability in the endoscopy units of our country is growing, and EUS has turned into a mainstay of the management of many digestive diseases. Oncologic pathology (digestive or not) probably represents the most common indication for EUS $(2,3)$.

High diagnostic accuracy and low rates of complications have consolidated EUS as the technique of choice in the locoregional staging of many neoplasms occasionally replacing previous diagnostic options (CT or MRI). However, in the clinical practice, the therapeutic decision about these patients does not depend only on the information provided by EUS, but it uses to be multidisciplinary management (surgeons, gastroenterologists, oncologists, internal medicine specialists, pneumologists...). EUS assessment represents another step in the multidisciplinary evaluation process, and considerations about EUS findings by different specialists vary widely. Few studies have assessed the therapeutic and economic impact of EUS(4). Controlled studies about this issue are needed in order to determine the real importance of EUS in clinical practice.

\section{AIM}

To determine the real therapeutic impact of EUS on a prospective cohort of non-selected patients referred to the 
Table I. Indications for Endoscopic Ultrasonography. European Society of Gastrointestinal Endoscopy (ESGE) guidelines $(2,3)$

\begin{tabular}{|c|c|}
\hline Patologhy & Indication \\
\hline Esophageal Cancer & $\begin{array}{l}\text { Preoperative staging } \\
\text { Assessment of resectability in operable } \\
\text { patients without distant metastases }\end{array}$ \\
\hline Gastric cancer & $\begin{array}{l}\text { Preoperative staging in operable patients } \\
\text { without distant metastases }\end{array}$ \\
\hline Submucosal tumors & $\begin{array}{l}\text { To confirm the diagnosis (differentiation } \\
\text { from extraluminal compression) } \\
\text { To plan therapy (resection or follow-up) }\end{array}$ \\
\hline Large gastric folds & $\begin{array}{l}\text { To characterize and exclude intramural } \\
\text { vessels prior to large-particle biopsy }\end{array}$ \\
\hline Pancreatic cancer & $\begin{array}{l}\text { Complementary to ERCP in cases in which } \\
\text { US and CT are negative or inconclusive } \\
\text { Local staging of potentially resectable } \\
\text { pancreatic cancers, together with other } \\
\text { procedures such as US, CT, angiography, } \\
\text { and laparoscopy }\end{array}$ \\
\hline $\begin{array}{l}\text { Pancreatic Endocrine } \\
\text { Tumors }\end{array}$ & $\begin{array}{l}\text { Preoperative localization in those with } \\
\text { potential pancreatic origin }\end{array}$ \\
\hline Chronic pancreatitis & Diagnose \\
\hline $\begin{array}{l}\text { Tumors of the Papilla } \\
\text { of Vater }\end{array}$ & Local preoperative staging \\
\hline Biliary tumors & $\begin{array}{l}\text { Preoperative staging in distal bile duct } \\
\text { tumors }\end{array}$ \\
\hline Gallstones & $\begin{array}{l}\text { In selected patients with negative or } \\
\text { inconclusive US for gallbladder stones }\end{array}$ \\
\hline Colorectal carcinoma & Preoperative staging of rectal cancer \\
\hline $\begin{array}{l}\text { Inflammatory Bowel } \\
\text { Disease }\end{array}$ & $\begin{array}{l}\text { Diagnosis of pararectal abscesses and } \\
\text { fistulas complementary to endoscopy }\end{array}$ \\
\hline Anal Incontinence & $\begin{array}{l}\text { As a valuable addition to other diagnostic } \\
\text { tests }\end{array}$ \\
\hline
\end{tabular}

Endoscopy Unit of a third-level hospital for diagnostic EUS.

\section{METHODS}

\section{Study design}

Prospective design study carried out in two different hospitals. All patients referred for diagnostic EUS over a period of 24 months were considered candidates to take part in the study if they met the following criteria:

Inclusion criteria: 1. Patient older than 18 years. 2. EUS indication according the European Society of Gastrointestinal Endoscopy guidelines (2,3) (table I). Exclusion criteria: 1 . Serious coagulopathy: platelets $<50.000$ and/or Prothrombine activity $<50 \%$. 2. Patient rejected to take part in the study.

All the EUS explorations were performed by an expert echoendoscopist (> 5 year and $>5000$ EUS performed). Only one echoendoscopist took part of this study (EVS). All the explorations were performed as an out-patient (excepting those patients admitted for other reasons), in a conventional endoscopic room and under conscious sedation controlled by endoscopist (Mydazolam, Propofol, Fentanyl and Pethidine with doses adjusted according to patient). EUS exam was performed with radial echoendoscope Olympus GF-UM160 (5-20 MHz, processor EU-M60) and/or linear echoendoscope Olympus GFUCT160-OL5 (7.5MHz, processor EU-C60). EUS-guided puncture (EUS-FNA) was performed with linear echoendoscope and puncture needle EUS-N1 Cook® of $22 \mathrm{G}$ or $19 \mathrm{G}$, following conventional technique, only in those patients in which it was requested by clinical practice.

\section{EUS technique}

To perform EUS of the upper digestive tract the echoendoscope was introduced into the duodenal second portion, were the exploration started evaluating the head of the pancreas, the biliary tree and hepatic hilum. During the withdrawal, duodenal bulb, gastric antrum and body, subcardial region and esophagus were explored (evaluating both the digestive wall and the adjacent structures), emphasizing in those areas related with the specific indication of EUS in every case. EUS of the lower digestive tract was performed entering the echoendoscope as far as $25-30 \mathrm{~cm}$ from anal margin, where the exploration started evaluating the bifurcation of the iliac arteries. During the withdrawal, rectal and anal wall and adjacent structures were explored.

\section{Estimation of the therapeutic impact}

At the end of each EUS, the echoendoscopist that performed it noted down if, according to his criteria, EUS provided new information about the pathology in study not previously known with other diagnostic tests (CT, MRI, etc) (new information provided by EUS: YES / NO). The echoendoscopist also noted if, in his opinion, that new information was clinically significant, and so, it should modify the management of the patient (theorical impact of EUS on treatment: YES / NO). Later, those doctors in charge of each patient, either separately or in the bosson of multidisciplinary committees, decided the most advisable therapy for the patient (no treatment/observation, surgery, chemo-radiotherapy...). That final decision was made considering EUS findings and also analytic, radiologic and demographic factors (age, sex, toxic habits, comorbidities,...) of the patients. Based on this information, real impact of EUS in this cohort of patients was estimated (real impact of EUS: YES / NO). It was analyzed if information provided by EUS and the other factors described was associated with a change in the therapeutic management of the patients. In those cases in which therapeutic decision was modified after EUS, it was determined if the new evidence provided by EUS favored a 
Table II. Basal data of the patients included in the study $(n=700)$

\begin{tabular}{|c|c|c|}
\hline Variable & $n=700$ & $\%$ \\
\hline \multicolumn{3}{|l|}{ Age (years) } \\
\hline Mean \pm S.D. & $59.0 \pm 15.6$ & \\
\hline Median & 57 & \\
\hline \multicolumn{3}{|l|}{ Sex } \\
\hline Male/Female & 399/301 & $57 / 43$ \\
\hline Tobacco (Yes/No) & $378 / 322$ & $54 / 46$ \\
\hline Mean $(\mathrm{cig} / \mathrm{d}) \pm$ S.D. & $13.7 \pm 15.2$ & \\
\hline Alcohol (Yes/No) & $441 / 259$ & $63 / 37$ \\
\hline Mean $(g / d) \pm S . D$. & $29.7 \pm 15.2$ & \\
\hline Median $(\mathrm{g} / \mathrm{d})$ & 32 & \\
\hline Cardiopathy (Yes/No) & $105 / 595$ & $15 / 85$ \\
\hline Diabetes M. (Yes/No) & $63 / 637$ & $9 / 81$ \\
\hline COPD (Yes/No) & $62 / 638$ & $9 / 81$ \\
\hline \multicolumn{3}{|l|}{ Previous endoscopy } \\
\hline HDE (Yes/No) & $553 / 147$ & $79 / 21$ \\
\hline EUS (Yes/No) & $56 / 644$ & $8 / 92$ \\
\hline
\end{tabular}

S.D.: Standard deviation. COPD: Chronic Pulmonary Obstructive Disease. HDE: High tract digestive endoscopy. EUS: Endoscopic Ultrasonography.

more or less aggressive treatment. (post-EUS treatment: more/less aggressive).

The next clinical case serves as an example to describe our approach to the estimation of the impact of EUS in this cohort of patients: 58 year old patient without relevant medical history, with a recent endoscopic diagnose of adenocarcinoma of the rectum, and computer tomography (CT) showed no extraparietal extension or lymph node/distant metastases (CT Stage T2N0); EUS is performed reporting tumoral invasion outside the muscularis propria, with no lymph node affectation (EUS stage T3N0); the patient is evaluated by the Committee of Tumors, that decide that new evidence provided by EUS (transmural invasion), not demonstrated by CT, must favor a change the management of the patient, adding previous neoadjuvant therapy to surgical intervention alone. In this case EUS provided new information (YES), in regard with echoendoscopists opinion this new information should influence the management of the patient (theoretical impact of EUS on treatment: YES). Consensus decision achieved by the committee of tumors modifying the treatment, adding neoadjuvant therapy, according to new evidence provided by EUS, should determine the real therapeutic impact (real impact of EUS: YES) and treatment would have been modified, adopting a more aggressive therapeutic strategy (add neoadjuvant therapy to surgery alone) (post-EUS treatment: more aggressive).

\section{Statistical analysis}

Statistical analysis of the data obtained in this study was made with the computer program JMP 7.0.2 (SAS Institute Inc., North Carolina, USA). Descriptive analysis of the variables was made:
Table III. Indications for EUS in the cohort of patients included in the study

\begin{tabular}{lcc}
\hline Indication & Absolute frequency (n) & Percentage \% \\
\hline Pancreatic/Biliary tumor & $134 / 700$ & $19 \%$ \\
Esophageal/gastric tumor & $133 / 700$ & $19 \%$ \\
Chronic/idiopathic Pancreatitis & $133 / 700$ & $19 \%$ \\
Subepitelial tumor & $132 / 700$ & $19 \%$ \\
Rectal tumor & $77 / 700$ & $11 \%$ \\
Portal Hipertension & $49 / 700$ & $7 \%$ \\
Gastric MALT Lymphoma & $42 / 700$ & $6 \%$ \\
\hline
\end{tabular}

a.) Discrete variables: were described as percentage and confidence interval of $95 \%$; b.) Continuous variables (normal distribution: mean, standard deviation and range), (non-normal distribution: median, interquartil range and range). In the univariated comparative analysis of the variables, statistical test used were $\mathrm{Chi}^{2}$ and Fisher Exact (discrete variables) and ANOVA and $\mathrm{H}$ of Kruskal-Wallis (continuous variables). Multivariated analysis of therapeutic impact of EUS and the rest of the data gathered (sex, tobacco consumption, comorbidities...) was made by means of multiple logistic regression (the age of the patient and alcohol consumption were considered for this kind of analysis as $\geq$ than the median in this cohort of patients, 57 years old and 32 $\mathrm{g}$ /day: YES or NO). The level of statistical significance was established in $\alpha=0.05$.

\section{RESULTS}

\section{Basal data of the patients included}

In the period of time described, a total of 700 consecutive patients that met the requirements of the study were included. Mean age of the patients included was 59 years old (range 14-91) with little predominance of men (57\%). $54 \%$ of the patients consumed tobacco and $63 \%$ revealed regular alcohol intake. In relation to the presence of comorbidities, $15 \%$ of the patients had any kind of a cardiopathy, 9\% were diabetics and 9\% met clinical criteria for chronic obstructive pulmonary disease (COPD). Seventy nine percent of the patients had an endoscopic procedure done before (table II). Most common indications for EUS were: pancreas/biliary tree tumor, esophageal/ gastric tumor, chronic/idiopathic pancreatitis and subepithelial tumor (table III).

\section{Analysis of therapeutic of EUS (Table IV)}

"New information": According to echoendoscopist criteria, EUS provided information (about the pathology in study) not previously known by other diagnostic tests in $89 \%$ of the patients evaluated (625 of 700 patients). 
Table IV. Impact of EUS in the treatment of this cohort of patients

\begin{tabular}{|c|c|c|c|}
\hline Therapeutic Impact & $\begin{array}{c}\text { Upper EUS } \\
n(\%, 95 \% \text { C.I.) }\end{array}$ & $\begin{array}{c}\text { Lower EUS } \\
n(\%, 95 \% \text { C.I. })\end{array}$ & $\begin{array}{c}\text { Overall } \\
n(\%, 95 \% \text { C.I. })\end{array}$ \\
\hline New information in EUS & $\begin{array}{c}554 / 623 \\
(89 \%, 86-91 \%)\end{array}$ & $\begin{array}{c}71 / 77 \\
(92 \%, 84-97 \%)\end{array}$ & $\begin{array}{c}625 / 700 \\
(89 \%, 87-91 \%)\end{array}$ \\
\hline Theoretical impact of EUS & $\begin{array}{c}480 / 623 \\
(77 \%, 74-80 \%)\end{array}$ & $\begin{array}{c}70 / 77 \\
(91 \%, 82-96 \%)\end{array}$ & $\begin{array}{c}550 / 700 \\
(79 \%, 75-82 \%)\end{array}$ \\
\hline Real Impact of EUS & $\begin{array}{c}414 / 623 \\
(66 \%, 63-70 \%)\end{array}$ & $\begin{array}{c}55 / 77 \\
(71 \%, 60-81 \%)\end{array}$ & $\begin{array}{c}469 / 700 \\
(67 \%, 63-70 \%)\end{array}$ \\
\hline
\end{tabular}

${ }^{\star}$ C.I.: Confidence Interval.

"Theoretical impact": Echoendoscopist estimated that new information provided by EUS should favor a change in the treatment in $79 \%$ of the patients included.

"Real impact": However, final decision taken by doctors in charge of the patients (considering EUS infomation and all the available data: age, comorbilities, other image tests, etc) was only modified in $67 \%$ of the patients. Final therapeutic strategy after EUS, taking into account all the factors described above, was less aggressive that the strategy before EUS in $34 \%$ of the patients.

Univariate and multivariate analysis (multiple logistic regression) demonstrated that changes in the final therapeutic strategy (real impact), less aggressive, were significantly associated with the next analyzed factors: 1 . EUS findings, 2. Alcohol intake ( $\geq 32 \mathrm{~g} /$ day) and 3 . Advanced age $(\geq 57$ years old $)(\mathrm{p}<0.05)$. The other factors analyzed (sex, tobacco consumption, diabetes, COPD, cardiopathy) were not significantly associated with changes in the therapeutic attitude $(\mathrm{p}>0.05)($ table $\mathrm{V})$.

Table V. Univariated and multivariated analysis of the factors statistically associated with changes in the therapeutic attitude in this cohort of patients

\begin{tabular}{ll}
\hline Variable & Statistical significance \\
\hline EUS findings & $\mathrm{P}<0.05$ (uni/multivariate) \\
Age $\left(>57\right.$ years old $\left.{ }^{\prime}\right)$ & $\mathrm{P}<0.05$ (uni/multivariate) \\
Sex & $\mathrm{P}=0.7$ \\
Smoker & $\mathrm{P}=0.8$ \\
Alcohol $(\geq 32 \mathrm{~g} / \mathrm{d})^{2}$ & $\mathrm{P}<0.05$ (uni/multivariate) \\
Cardiopathy & $\mathrm{P}=0.9$ \\
COPD & $\mathrm{P}=0.5$ \\
Diabetes Mellitus & $\mathrm{P}=0.7$ \\
\hline
\end{tabular}

1,2 Median of age and alcohol consumption.

Note: (The age of the patient and alcohol intake are considered for this type of analysis as > than the median of this cohort of patients, 57 years old and 32 g/day: YES or NO).

\section{DISCUSSION}

EUS has become one of the main tools for the study of a great variety of diseases. This is mainly due to its ability to reproduce high quality images in real time and in hard access locations, allowing in addition, obtention of the histological tissue samples with a low rate of complications. However, there are no contrasted data supporting if the perception that gastroenterologists in general, and echoendoscopists in particular, have about EUS usefulness is real, or on the other hand, EUS only provides known information previously acquired by other non-invasive diagnostic tests. Results of this controlled study shows that EUS provides new information (not known before performing EUS) in $89 \%$ of the patients evaluated. These data are in accordance with previous studies (5-30).

Results about the therapeutic impact of EUS in the cohort of patients described in this study are similar to those described by Giovannini and cols (31). This group retrospectively reviewed their experience in the field of EUS for 11 years, in which they performed diagnostic EUS in more than 1500 patients with digestive tumors. The study published by Giovannini assessed effectiveness, safety and clinical (therapeutic) impact of EUS and EUS-FNA in this retrospective cohort of patients. Sensitivity, specificity and diagnostic accuracy were $84.6 \%, 98.4 \%$ and $86.9 \%$, respectively. EUS-FNA allowed the obtention of adequate tissue samples for cytological study in $80-85 \%$ of the cases, and avoided the realization of most aggressive techniques, with higher morbid-mortality, in $44 \%$ of the patients. In the study of Giovannini, from what authors said, EUS/EUS-FNA modified the diagnosis and/or therapeutic attitude in 1801 patients of 1544 (70.1\%). These data are similar to that demonstrated in our study (real impact of EUS on treatment, 67\%). Specifically, in the study of Giovannini, in 161 patients with esophageal, gastric, pancreatic or rectal tumors, the finding of metastatic lymph nodes according to TNM system, as well as little 
hepatic implants, not described by CT, modified therapeutic strategy. Likewise, in 242 patients with solid pancreatic lesions (previously described by other image diagnostic tests), EUS-FNA result modified therapeutic strategy after cytopathological classification of the tumor.

Recently, Ginés et al. published a critical review of the existent literature about the impact of EUS and EUS-FNA in the diagnosis of the extent, management, prognosis, survival and economics in esophageal cancer (4). This analysis and critical review of the literature is, in our opinion, more realistic than the study of Giovannini, and what it shows is the great disagreement among the different studies performed evaluating therapeutic impact (32-37). In these studies, utility and impact of EUS range between $26 \%(32,33)$ and $80 \%$ (37). This great variability could be justified, at least in part, due to the heterogeneity of the methodology used in the different studies when quantifying therapeutic impact, and due to the differences in the design of the studies. The systematic review performed by Ginés et al. reveals how difficult is to estimate adequately the real utility of EUS in this indication due to the existence of few controlled data. This happens in similar way in other pathologies in which EUS is usually indicated, as for example, pancreatic cancer. Though EUS can avoid surgical obtaining of histological diagnosis of the nature of a pancreatic tumor in more than $80 \%$ of the cases, therapeutic impact of EUS-FNA varies widely depending the study consulted (from 30 to $70 \%$ of the patients) (38, $39,40)$. It has been suggested than methodological differences among studies and, above all, the different perception and approval on the part of the surgeons and oncologists of the information provided by EUS/EUS-FNA could be responsible of the differences observed.

Existent data about impact of EUS/EUS-FNA in rectal cancer (EUS helps to detect those patients with locally advanced disease in which preoperatory neoadjuvant treatment will be beneficial) are less optimistic. The published studies estimate a therapeutic impact of EUS in this pathology around 32\% (41). The development and implantation of MRI as the common tool in loco-regional staging in rectal cancer may be related with this limited impact. Specifically, mesorectal affectation is one of the main factors that surgeons and oncologistis take into account to make the right decision. This information is provided accurately by MRI and not by EUS. However, results from our study suggest that information provided by EUS in this pathology (fundamentally perirectal fat tissue and malignant lymph nodes affectation) has a real impact in the treatment of $71 \%$ of the patients, irrespective of mesorectal affectation.

To avoid part of the methodological problems described, in this study we have intended to evaluate in a prospective, controlled and systematized way the data described in methods section:

1. "EUS provides new information";

2. "Theoretical impact of EUS";
3. "Real impact of EUS";

4. "Post-EUS treatment" (more/less aggressive or the same).

Though items 1 and 2 are subjective estimations of the echoendoscopist of the efficacy of EUS (probable bias in favor of EUS) items 3 and 4 reflect objectively if there has been a change in therapeutic attitude. When there is a change in therapeutic attitude, statistical analysis will show if this change is associated or not with EUS findings and with other factors, what will measure in a real way the impact of EUS. Differences between items 1 and 2 vs. 3 and 4 probably reflect the excessively magnified perception that the endosonographers have about the efficacy of EUS against the perception of the doctors that look after these patients daily. However, some authors suggest that it is also possible that part of the information provided by EUS is not adequately recognized or understood by the doctors that request this test. This hypothesis is sustained in the results of studies as the published by Maple and cols (42), in which they asses the use of EUS on the part of thoracic surgeons. In this study, up to $85 \%$ of the surgeons polled consider adequate the realization of EUS in the preoperative staging of esophageal cancer, though only $50 \%$ of them recognize to request it in their clinical practice. On the other hand, in this study $16-29 \%$ of the surgeons recognize, though the existence of solid evidence favoring the use of EUS, that they consider CT and PET the most accuracy diagnostic test for T$\mathrm{N}$ staging of these patients. In this same study, Maple et al. evidence that youngest surgeons and those with access to endoscopy units with higher experience, are most inclined to request EUS during the preoperative study of this kind of tumors. Perhaps a better popularization of EUS indications and usefulness, should help to reduce the current differences between the theorical impact (determined by the echoendoscopist) and the real impact (determined by the doctor in charge of the final therapeutic decision), as the results of our study reflect.

In our opinion, one of the most relevant findings of the present study is the change in the therapeutic attitude experienced in 2 out of every 3 patients evaluated (67\%) after the realization of EUS. This change in the therapeutic attitude was independent of if the indication was EUS of the upper (66\% of changes in the therapeutic attitude) or lower digestive tract $(71 \%)$. Univariated and multivariated analysis (multiple logistic regression) showed that EUS findings (echoendoscopist opinion), an advanced age of the patient ( $\geq 57$ years old) and alcohol intake ( $\geq$ $32 \mathrm{~g} /$ day), were associated in a statistically significant way to changes in the final therapeutic attitude, which was less aggressive (Table V). We think that this result is of great clinical relevance, because it makes clear that the information provided by EUS, with the other data, has a real impact in clinical practice in those patients referred for EUS. In our opinion, these results justify the use of EUS in the clinical practice in those indications described in table I. 
On the other hand, we also think that it is important to stand out that in approximately a third of patients included in the study, the final therapeutic decision was less aggressive than what it would have been adopted without the realization of EUS (Table IV). Though cost analysis was not among the aims of this study, the fact that the information provided by EUS allows avoiding the realization of more aggressive tests and/or treatments in $34 \%$ of patients, should have a significant impact in order to reduce the costs derived of the diagnose and treatment of the different pathologies evaluated in this study. This hypothesis is in accordance with the results of the cost-effectiveness and cost-minimization published studies $(28,43,44)$.

In conclusion, results of this prospective study provide objective and controlled data about the real utility of EUS for the study, diagnose and therapeutic decision of the patients referred for diagnostic EUS. These results suggest that the age of the patient, alcohol intake and EUS findings influence in a significant way the treatment received by the patients. EUS findings favor a less aggressive treatment in almost a third of patients. Economic implications of these findings should be analyzed in future studies. The results of this study support the routine use of EUS for the referred indications.

\section{REFERENCES}

1. Sivak MV Jr. Evidence-based endoscopy. Gastrointest Endosc 2002; 56(6):948-50.

2. Guidelines of the European Society of Gastrointestinal Endoscopy (E.S.G.E.). Endoscopic ultrasonography. Part I: Technique and upper gastrointestinal tract. European Endosonography Club. Endoscopy 1996; 28(5):474-6.

3. Caletti G, Deviere J, Fockens P, Lees WR, Mortensen B, Odegaard S, Rösch T, Souquet JS, Vilmann P. Guidelines of the European Society of Gastrointestinal Endoscopy (ESGE) Part II: Retroperitoneum and large bowel, training. The European Endosonography Club Working Party. Endoscopy 1996; 28(7):626-8.

4. Ginès $\mathrm{A}$, Fernández-Esparrach $\mathrm{G}$, Pellisé $\mathrm{M}$, Llach-Osendino J, Mata A, Bordas JM. Impact of endoscopic ultrasonography (EUS) and EUS-guided fine-needle aspiration (EUS-FNA) in the management of patients with esophageal cancer. A critical review of the literature. Gastroenterol Hepatol 2006; 29(5):314-9

5. Polkowski M. Endosonographic staging of upper intestinal malignancy. Best Pract Res Clin Gastroenterol 2009; 23(5): 649-61.

6. Vázquez-Sequeiros E, Norton ID, Clain JE, Wang KK, Affi A, Allen M, Deschamps C, Miller D, Salomao D, Wiersema MJ.. Impact of EUS-guided fine-needle aspiration on lymph node staging in patients with esophageal carcinoma. Gastrointest Endosc 2001; 53(7):751-7.

7. Murata Y, Suzuki S, Hashimoto H. Endoscopic ultrasonography of the upper gastrointestinal tract. Surg Endosc 1988; 2(3):180-3.

8. Tio TL, Coene PP, Den Hartog Jager FC, Tytgat GN. Preoperative TNM classification of esophageal carcinoma by endosonography. Hepatogastroenterology 1990; 37(4):376-81.

9. Vilgrain V, Mompoint D, Palazzo L, Menu Y, Gayet B, Ollier P, Nahum H, Fekete F. Staging of esophageal carcinoma: comparison of results with endoscopic sonography and CT. AJR Am J Roentgenol 1990; 155(2):277-81.

10. Botet JF, Lightdale CJ, Zauber AG, Gerdes H, Urmacher C, Brennan MF. Preoperative staging of esopagheal cancer: comparison of endoscopic US and dynamic CT. Radiology 1991; 181(2): 419-25.

11. Grimm H, Binmoeller KF, Hamper K, Koch J, Henne-Bruns D, Soehendra N. Endosonography for preoperative locorregional staging of esophageal and gastric cancer. Endoscopy 1993; 25(3):224-30.
12. Rosch T, Lorenz R, Zencker K, von Wichert A, Dancygier H, Höfler $\mathrm{H}$, Siewert JR, Classen M. Local staging and assessment of respectability in carcinoma of esophagus, stomach and duodenum by endoscopic ultrasonography. Gastrointest Endosc 1992; 38(4):460-7.

13. Sandha GS, Severin D, Postema E, McEwan A, Stewart K. Is positron emission tomography useful in locoregional staging of esophageal cancer? Results of a multidisciplinary initiative comparing CT, positron emission tomography, and EUS. Gastrointest Endosc 2008; 67 (3): 402-9.

14. Catalano MF, Alcocer, E, Chak A, Nguyen CC, Raijman I, Geenen JE, Lahoti S, Sivak MV. Evaluation of metastatic celiac axis lymph nodes in patients with esophageal carcinoma: accuracy of EUS. Gastrointest Endosc 1999;50(3):352-6.

15. Pech O, May A, Günter E, Gossner L, Ell C. The Impact of Endoscopic Ultrasound and Computed Tomography on the TNM Staging of Early Cancer in Barrett's Esophagus. Am J Gastroenterol 2006; 101(10):2223-9.

16. Vázquez-Sequeiros E, Ginès A, Wiersema MJ. Role of ultrasoundguided endoscopy in the evaluation of mediastinal lesions. Med Clin (Barc) 2003;121(6):231-7.

17. Gress FG, Savides TJ, Sandler A, Kesler K, Conces D, Cummings O, Mathur P, Ikenberry S, Bilderback S, Hawes R. Endoscopic ultrasonography, fine needle aspiration biopsy guided by endocopic ultrasonography and computed tomography in the preoperative staging of non-samll-cell lung cancer: a comparison study. Ann Intern Med 1997; 127(8 Pt 1): 604-12.

18. The Information Committee of the Korean Gastric Cancer Association. 2004 Nationwide gastric cancer report in Korea. J Korean Gastric Cancer Assoc 2007; 7:47-54.

19. Ahn HS, Lee HJ, Yoo MW, Kim SG, Im JP, Kim SH, Kim WH, Lee KU, Yang HK. Diagnostic Accuracy of T and N Stages With Endoscopy, Stomach Protocol CT, and Endoscopic Ultrasonography in Early Gastric Cancer. J Surg Oncol 2009; 99(1):20-7.

20. Sano T, Okuyama Y, Kobori O, Shimizu T, Morioka Y. Early gastric cancer. Endoscopic diagnosis of depth of invasion. Dig Dis Sci 1990; 35(11):1340-4

21. Bhandari S, Shim CS, Kim JH, Jung IS, Cho JY, Lee JS, Lee MS, Kim BS. Usefulness of threedimensional, multidetector row CT (virtual gastroscopy and multiplanar reconstruction) in the evaluation of gastric cancer: A comparison with conventional endoscopy, EUS, and histopathology. Gastrointest Endosc 2004;59(6):619-626.

22. Ganpathi IS, So JB, Ho KY. Endoscopic ultrasonography for gastric cancer: Does it influence treatment? Surg Endosc 2006; 20(4):559562.

23. Iglesias-García J, Lariño-Noia J, Domínguez-Muñoz J.E. Endoscopic ultrasound in the diagnosis and staging of pancreatic cancer. Rev Esp Enf Dig 2009;101(9):631-8.

24. Lockhart AC, Rothenberg ML, Berlin JD. Treatment for pancreatic cancer: Current therapy and continued progress. Gastroenterology 2005;128(6):1642-54.

25. Harewood GC, Wiersema MJ. Endosonography-guided fine needle aspiration biopsy in the evaluation of pancreatic masses. Am J Gastroenterol 2002; 97(6): 1386-91.

26. Eloubeidi MA, Chen VK, Eltoum IA, Jhala D, Chhieng DC, Jhala N Vickers SM, Wilcox CM. Endoscopic ultrasound-guided fine needle aspiration biopsy of patients with suspected pancreatic cancer: diagnostic accuracy and acute and 30-days complications. Am J Gastroenterol 2003; 98(12): 2663-8.

27. Iglesias-Garcia J, Dominguez-Muñoz E, Lozano-Leon A, Abdulkader I, Larino-Noia J, Antunez J, Forteza J. Impact of endoscopic-ultrasound fine needle biopsy for diagnosis of pancreatic masses World J Gastroenterol 2007; 13(2): 289-93.

28. Harewood GC, Wiersema MJ. Cost-Effectiveness of Endoscopic Ultrasonography in the Evaluation of Proximal Rectal Cancer. Am J Gastroenterol 2002; 97 (4):874-82.

29. Kwok H, Bissett IP, Hill GL. Preoperative staging of rectal cancer Int J Colorectal Dis 2000; 15(1):9-20.

30. Meyenberger C, Huch Böni RA, Bertschinger P, Zala GF, Klotz HP Krestin GP. Endoscopic ultrasound and endorectal magnetic resonance imaging: A prospective, comparative study for preoperative staging and follow-up of rectal cancer. Endoscopy 1995; 27(7):469-79.

31. Giovannini M, Kethu SR, G.Monges, E.Boriés, Ch.Pesenti, C.Danisi. Results and clinical impact of EUS-FNA. Results of 11 year expe- 
rience in more than 1500 patients. Rev Esp Ecog Digest 2005; 7e(0): Art 2.

32. Douglas A. Shumaker, MD, Patricia de Garmo, ANP, Douglas O. Faigel, MD. Potential impact of preoperative EUS on esophageal cancer management and cost. Gastrointest Endosc 2002;56(3):391-6.

33. Nickl NJ, Bhutani MS, Catalano M, Hoffman B, Hawes R, Chak A, Roubein LD, Kimmey M, Johnson M, Affronti J, Canto M, Sivak M, Boyce HW, Lightdale CJ, Stevens P, Schmitt C. Clinical implications of endoscopic ultrasound: the American Endosonography Club Study. Gastrointest Endosc 1996; 44(4):371-7.

34. Vazquez-Sequeiros E, Wiersema MJ, Clain JE, Norton ID, Levy MJ, Romero Y, Salomao D, Dierkhising R, Zinsmeister AR. Impact of lymph node staging on therapy of esophageal carcinoma. Gastroenterology 2003; 125(6): 1626-35.

35. Giovannini M, Monges G, Seitz JF, Moutardier V, Bernardini D, Thomas P, Houvenaeghel G, Delpero JR, Giudicelli R, Fuentes P. Distant lymph node metastases in esophageal cancer: impact of endoscopic ultrasound-guided biopsy. Endoscopy 1999; 31(7): 536-40.

36. Gines A, Cassivi SD, Martenson JA Jr, Schleck C, Deschamps C, Sinicrope FA, Alberts SR, Murray JA, Zinsmeister AR, Vazquez-Sequeiros E, Nichols FC 3rd, Miller RC, Quevedo JF, Allen MS, Alexander JA, Zais T, Haddock MG, Romero Y. Impact of ultrasonography and physician specialty on the management of patients with esophagus cancer. Dis Esophagus 2008;21(3): 241-250.

37. Preston SR, Clark GW, Martin IG, Ling HM, Harris KM. Effect of endoscopic ultrasonography on the management of 100 consecutive patients with oesophageal and junctional carcinoma. Br J Surg 2003; 90(10):1220-4.

38. Mortensen MB, Edwin B, Hünerbein M, Liedman B, Nielsen HO, Hovendal C. Impact of endoscopic ultrasonography (EUS) on surgical decision-making in upper gastrointestinal tract cancer: an international multicenter study. Surg Endosc 2007;21(3):431-8.

39. Erickson RA, Garza AA. Impact of endoscopic ultrasound on the management and outcome of pancreatic carcinoma. Am J Gastroenterol 2000; 95(9):2248-54.

40. Chang KJ, Nguyen P, Erickson RA, Durbin TE, Katz KD. The clinical utility of endoscopic ultrasound-guided fine-needle aspiration in the diagnosis and staging of pancreatic carcinoma. Gastrointest Endosc 1997;45(5):387-93.

41. Harewood GC. Assesment of clinical impact of endoscopic ultrasound on rectal cancer. Am J Gastroenterol 2004;99 (4):623-7.

42. Maple JT, Peifer KJ, Edmundowicz SA, Early DS, Meyers BF, Jonnalagadda S, Azar RR. The impact of endoscopic ultrasonography with fine needle aspiration (EUS-FNA) on esophageal cancer staging: a survey of thoracic surgeons and gastroenterologists. Dis Esophagus 2008;21(6):480-7.

43. Harewood GC, Wiersema MJ. A cost analysis of endoscopic ultrasound in the evaluation of esophageal cancer. Am J Gastroenterol 2002;97(2):452-8.

44. Harewood GC, Wiersema MJ. A cost analysis of endoscopic ultrasound in the evaluation of pancreatic head adenocarcinoma. Am J Gastroenterol 2001;96(9):2651-6. 